\title{
"Perdeu a veia" - significados da prática da terapia intravenosa na unidade de terapia intensiva neonatal
}

\author{
"The vein is missed" - meanings of intravenous therapy practice \\ in Neonatal Intensive Care Unit
}

Elisa da Conceição Rodrigues ${ }^{1}$

Sueli Rezende Cunha ${ }^{2}$

Romeu Gomes ${ }^{3}$

${ }^{1}$ Departamento de

Enfermagem

Materno-Infantil, Escola de

Enfermagem Anna Nery,

Universidade Federal do

Rio de Janeiro. Rua Afonso

Cavalcanti 275, Cidade

Nova. 20211-110 Rio de

Janeiro RJ.

elisaelisa@terra.com.br

${ }^{2}$ Núcleo de Pesquisa em

Ciência, Tecnologia e

Inovação em Saúde,

Fundação Oswaldo Cruz.

${ }^{3}$ Departamento de Ensino,

Instituto Fernandes

Figueira, Fundação Oswaldo

Cruz.

\begin{abstract}
Intravenous Therapy (IVT) is an important item among the necessary technologies for the survival of high-risk new-born babies. However, it is also a source of pain, stress and risk of serious complications. This article aims to assess the meanings of IVT as ascribed by care teams and to discuss the reflection of such meanings on the attention to new-born babies. The article, with a theoretical referential in Cultural Anthropology, presents an ethnographic case study carried out in a Neonatal Intensive Care Unit of municipal administration in Rio de Janeiro. Subjects were nine nurses, four doctors, and three nurse assistants. Data collection was carried out with a semi-structured interview and participative observation. The qualitative analysis was performed using the method of interpretation of the senses. Meanings, interweaved with the cultural network, showed that IVT practice is often reduced to peripheral puncture techniques, bringing on a series of complications for high risk new-born babies and intense emotional waste for the professional team and the family. Re-signification of IVT practice will only be possible with a critical analysis of the cultural patterns it is now based on.
\end{abstract}

Key Words New born babies, Infusion therapy, Nursing, Anthropology
Resumo A terapia intravenosa (TIV) destaca-se entre as tecnologias imprescindiveis para garantir a sobrevivência dos recém-nascidos de risco. Contudo, é fonte de dor, estresse e complicações graves. O objeto de estudo foram os significados da prática da terapia intravenosa na unidade de terapia intensiva neonatal (UTIN), mais especificamente: analisar os significados atribuídos à prática da TIV pela equipe e discutir como esses significados refletem no cuidado do recém-nascido. Trata-se de um estudo de caso etnográfico com referencial teórico da antropologia cultural, realizado em uma UTIN pública do município do Rio de Janeiro. Os sujeitos foram nove enfermeiros, quatro médicos, três técnicos e quatro auxiliares de enfermagem. Os dados foram coletados através de entrevista semiestruturada e observação participante. A análise qualitativa das entrevistas foi realizada utilizando-se o método da interpretação dos sentidos. Os significados, quando entrelaçados na "teia cultural", revelaram que a prática da TIV é reduzida a técnicas de punção venosa periférica, acarretando sérios agravos para os recém-nascidos e desgaste emocional para a equipe e a família. A ressignificação da prática da terapia intravenosa será possível a partir da reflexão crítica dos padrões culturais nos quais ela se estrutura.

Palavras-chave Recém-nascido, Terapia infusional, Enfermagem, Antropologia 


\section{Introdução}

Entre as diretrizes do Programa de Atenção Humanizada ao Recém-Nascido de Baixo Peso, a prevenção da dor e do estresse é um dos maiores desafios a serem vencidos para a implementação do paradigma de cuidado humanizado e voltado para o desenvolvimento. A ideia central dos programas de humanização do parto e do nascimento é prestar cuidados de saúde de alta qualidade de forma integral, com vistas a promover o desenvolvimento dos recém-nascidos e conforto e apoio para suas famílias ${ }^{1}$.

Nesse contexto, os conhecimentos sobre os efeitos da dor no recém-nascido e os determinantes biológicos e socioculturais para a sua prevenção, avaliação e tratamento já fazem parte da produção científica do campo da saúde. A difusão desses conhecimentos tem contribuído para modificar a crença de que recém-nascidos não sentem dor além de sugerir a incorporação de várias medidas para seu controle no ambiente de cuidados intensivos neonatais.

A terapia intravenosa (TIV) ocupa de destaque entre o conjunto de tecnologias que são imprescindíveis para a sobrevivência dos recémnascidos, contudo representam fonte importante de dor, estresse e risco para complicações potencialmente graves ${ }^{2}$.

A via intravenosa é o principal acesso para a administração de fármacos em recém-nascidos internados em UTIN, sendo vital para sua sobrevivência. Porém existem poucos estudos nacionais que forneçam subsídios para avaliação e melhoria dessa prática, a despeito de dois terços do tempo da equipe de enfermagem, destinados à criança hospitalizada, serem consumidos pela $\mathrm{TIV}^{3}$.

Um estudo realizado em cinco unidades neonatais do município do Rio de Janeiro concluiu que $99,6 \%$ dos recém-nascidos abaixo de 1500 gramas utilizaram fármacos e soluções intravenosas através de vários tipos de dispositivos intravasculares, sendo que $49,2 \%$ dos neonatos utilizaram somente dispositivo periférico, $45,2 \%$ dispositivo periférico e central e apenas 5,6\% utilizaram dispositivo central, apesar de o protocolo das unidades recomendar o acesso venoso central para recém-nascidos que necessitem de TIV por mais de sete dias e/ou com o uso de soluções irritantes ao endotélio venoso ${ }^{4}$. Outro estudo realizado no município do Rio de Janeiro demonstrou que a punção venosa periférica foi o procedimento mais realizado em bebês participantes da primeira etapa do Método-Canguru de uma maternidade pública federal ${ }^{5}$.
A prática da TIV é rotineira e familiar, contudo, o conhecimento produzido sobre o tema ainda é fragmentado e privilegia técnicas e procedimentos isolados a despeito de toda complexidade inerente a esse campo de saber. O conhecimento acerca de novos fármacos e de dispositivos intravasculares vem avançando mais rapidamente que as pesquisas voltadas para o cuidado das pessoas que os utilizam ${ }^{6}$.

Diante do que foi exposto, este artigo tem como objetivos analisar os significados atribuídos à prática da TIV pela equipe de uma UTIN e discutir como esses significados refletem no cuidado do recém-nascido. Conhecer os significados atribuídos pela equipe à prática da TIV poderá fornecer subsídios no avanço das discussões sobre uma das práticas mais rotineiras e indispensáveis à sobrevivência dos recém-nascidos de alto-risco.

\section{Abordagem teórico-metodológica}

O presente trata-se de um estudo de caso com abordagem etnográfica, desenvolvido na UTIN de uma maternidade pública, de referência no Método-Canguru, situada no município do Rio de Janeiro.

A etnografia é um método de pesquisa antropológica, no qual a interpretação das práticas culturais de determinado grupo é construída através de um trabalho de campo extensivo feito pelo etnógrafo. Um dos seus pressupostos é que cada grupo humano desenvolve sua própria cultura, que orienta a visão de mundo de seus membros e a forma como eles estruturam suas experiênci$\mathrm{as}^{7,8}$. A antropologia aplicada à área da saúde tem papel fundamental nos estudos em que o ato interpretativo possibilita o reconhecimento dos aspectos culturais relacionados ao processo saúde-doença, bem como a escolha, a promoção e a avaliação de ações terapêuticas ${ }^{9}$.

A abordagem etnográfica associada ao estudo de caso pode contribuir para mudanças de práticas nos diversos tipos de serviços, pois, ao incidir sobre representações e interpretações de ações de cuidado e ações organizacionais, favorece a apropriação de sentidos subjacentes a essas práticas, permitindo formas de intervenção mais reflexivas e críticas ${ }^{10}$. Além disso, os estudos de caso etnográficos vêm sendo valorizados por seu potencial heurístico, levando o pesquisador a descobrir novos significados e a estabelecer novas relações ${ }^{11}$.

As representações culturais sobre a prática da TIV são desconhecidas nos serviços de saúde. 
Deste modo, as peculiaridades inerentes ao estudo de caso associado à abordagem etnográfica possibilitaram desvendar o saber tácito, inscrito nos significados atribuídos a essa prática profissional em uma unidade de referência na Atenção Humanizada ao Recém-Nascido de Baixo Peso Método-Canguru.

A partir do estudo de um caso representativo do município do Rio de Janeiro, vislumbra-se a possibilidade de aproximação com modelos que estruturam a prática da TIV em outras unidades de referência do Método-Canguru, uma vez que, enquanto política nacional de saúde, a mesma fundamenta-se na perspectiva de minimizar os efeitos negativos da internação neonatal sobre os bebês e suas famílias ${ }^{12}$.

Ao perceber as instituições hospitalares como um complexo emaranhado de padrões simbólicos produzidos nas interações sociais e que precisam ser traduzidos para ser entendidos, é possível interpretar a forma como os sujeitos entendem suas experiências na prática e deduzir como essas experiências se relacionam com a prática efetivamente realizada. Esse exercício de interpretação pode vir a promover reflexões e discussões acerca do mundo do trabalho no contexto em foco ${ }^{13}$.

Para este estudo, as interpretações foram construídas através da lente da antropologia interpretativa, ou hermenêutica, onde o conceito de cultura é essencialmente semiótico, ou seja, um conjunto de significados e suas análises que se configuram numa teia criada pelo próprio homem e na qual ele permanece amarrado. Esta teia é dinâmica e sempre remodelada pelas constantes interações humanas, configurando a cultura como o produto dessas interações ${ }^{7}$. Os dados foram coletados no período de agosto de 2007 a março de 2008. Os sujeitos da pesquisa foram nove enfermeiros e quatro médicos, três técnicos e quatro auxiliares de enfermagem, totalizando 21 entrevistas. Os sujeitos receberam pseudônimos de cientistas que contribuíram para o avanço do conhecimento na área de terapia intravenosa.

As fontes primárias foram as anotações de campo obtidas através da observação participante e da entrevista semiestruturada. Compuseram o diário de campo, diálogos informais com os sujeitos, situações emblemáticas do cotidiano dos profissionais, informações retiradas de livros de ordem e ocorrências da enfermagem, prontuários, prescrições médicas e registros de enfermagem. As entrevistas foram gravadas e a coleta de dados encerrada quando foi observada a recor- rências de vários significados, os quais, juntamente com as anotações do diário de campo, deram origem às categorias empíricas. A pesquisa foi aprovada pelo Comitê de Ética em Pesquisa da Secretaria Municipal do Rio de Janeiro.

Neste estudo, buscou-se captar as estruturas de significação cultural que refletem os significados da prática da TIV pela equipe de saúde. A fala cultural dos sujeitos e as anotações do diário de campo foram traduzidas num corpus textual onde o conhecimento produzido foi fruto do encontro entre o pesquisador e os sujeitos no contexto histórico e intersubjetivo de ambos.

Os dados foram organizados e analisados através do método da interpretação dos sentidos (MIS), buscando-se a construção e a interpretação das estruturas de significação. As estruturas de significação representam a dupla hermenêutica do objeto, onde a interpretação é o ponto de partida, por se iniciar pela interpretação do pesquisador, e o ponto de chegada, porque é a interpretação das interpretações dos atores sociais sobre o seu cotidiano ${ }^{14}$.

O MIS foi idealizado a partir da perspectiva de correntes compreensivas das ciências sociais que analisa as palavras, as ações, o conjunto de inter-relações, os grupos, as instituições, as conjunturas e outros corpos analíticos, numa tentativa de avançar na interpretação, caminhando além dos conteúdos manifestos nos textos na direção de seus contextos e revelando lógicas e explicações mais abrangentes, presentes numa determinada cultura, acerca de um determinado tema ${ }^{14}$.

\section{Resultados e discussão}

\section{Decifrando os códigos da prática da terapia intravenosa}

A decodificação das expressões a seguir possibilitou a apreensão de algumas estruturas conceituais que, sem o olhar interpretativo e o movimento de estranhamento, permaneceriam ocultas, por estarem entrelaçadas umas às outras $e$ serem profundamente familiares, não só para a equipe como também para a pesquisadora. Os códigos decifrados, além de estarem presentes no cotidiano da UTIN durante toda a observação de campo, foram recorrentes em grande parte dos depoimentos. Portanto, selecionei alguns deles por considerá-los símbolos ou códigos que, quando decifrados, permitiram aprofundar a leitura dos significados atribuídos à prática da terapia intravenosa. 


\section{Uma "veinha"}

Uma interpretação possível para o significado de "veinha" no contexto da prática de terapia intravenosa é de que o termo seria utilizado pelos profissionais como referência à dimensão corporal diminuta dos recém-nascidos prematuros. Contudo, a interpretação dada ao termo pelos sujeitos traz a crítica ao significado atribuído a este código: Muita gente encara assim, é só uma veinha. Não é só uma veinha não. As pessoas acham normal, tão comum, que não param para se preocupar no que tem por trás disso... talvez porque tenha sido tomado como algo corriqueiro (...) é normal e comum ver um bebê com veia (Seibert, enfermeira).

A familiaridade da equipe com recém-nascidos portadores de acessos venosos dificulta a reflexão e a crítica sobre as implicações que esse dispositivo tem para o cuidado do recém-nascido. Nesse sentido, o termo "veinha" pode ser interpretado como a redução do cuidado do recém-nascido ao dispositivo intravenoso periférico em si, ficando invisível o impacto que a indicação, a instalação, a manutenção e a perda daquele acesso têm para o paciente ao longo de sua permanência na UTIN.

$\mathrm{Na}$ unidade estudada, a despeito de o plano terapêutico de grande parte dos recém-nascidos indicar a necessidade do uso de cateteres venosos centrais, a implementação da terapêutica intravenosa ainda é predominantemente realizada através de veias periféricas, caracterizando a inadequação do tipo de acesso às necessidades dos recém-nascidos. Alguns estudos recentemente realizados em unidades neonatais do município do Rio de Janeiro têm evidenciado essa mesma tendência ${ }^{4,5}$.

Atualmente, para minimizar os problemas de múltiplas punções venosas, lesões por infiltração, extravasamento e complicações infecciosas relacionadas à corrente sanguínea no recém-nascido pré-termo, a conduta mais aceita é a utilização precoce de acesso venoso central por cateteres centrais de inserção periférica².

À medida que avançamos na decodificação dos símbolos que permitem a leitura do saber local, percebemos que a banalização do uso de acessos venosos periféricos orienta a prática da terapia intravenosa na UTIN e coloca o profissional diante de recém-nascidos com esgotamento da rede venosa periférica, o que podemos constatar através de uma das expressões mais utilizadas pela equipe no dia-a-dia da UTIN: "a veia difícil".

\section{A “veia difícil”}

Durante a internação na UTIN, os bebês são classificados como portadores de veia fácil ou difícil. Nos depoimentos, os bebês que mais se destacaram foram os classificados como portadores de "veias difíceis", que provocam reclamação, desgaste e desânimo na equipe: Há aquela preocupação se é uma criança difícil ou fácil de veia. (Harvey, enfermeiro) Eu não punciono mais. Quem quiser ir vai, tipo aquele bebê lá, filho de $M L, 27$ dias de Cipro (Dudrick, auxiliar de enfermagem).

O bebê de "veia difícil" é aquele que já sofreu múltiplas punções venosas, tem a cabeça raspada, usou mais de um esquema de antibiótico, hidratações venosas e nutrição parenteral através das veias periféricas, o que levou ao esgotamento da rede venosa superficial. É nesses casos, que após algumas tentativas, o profissional pede ajuda: Geralmente quando o bebê já está muito furado, cortou o cabelo, está muito difícil de acesso eles chamam a gente. Até tentam, mas depois chamam a gente (Gautier, enfermeira). Paradoxalmente, a terapêutica intravenosa necessária para que os recém-nascidos sobrevivam causa a destruição da sua rede venosa periférica, sendo esse o contexto no qual emerge o bebê com a "veia difícil". Ao longo da internação, as "veinhas" tornam-se "veias difíceis", em consequência de múltiplas punções e da infusão de vários tipos de fármaco e diferentes soluções: Ah. meu Deus, vem o bebê que não tem veia, não tem nada, aí tem que puncionar, dai é complicado (Lister, auxiliar de enfermagem).

A "veia difícil” é consequência das dificuldades encontradas pelos profissionais, para manter os recém-nascidos em terapia intravenosa durante a internação e deve ser considerada uma complicação do uso frequente de acessos venosos periféricos que levam ao esgotamento da rede venosa e às múltiplas punções.

\section{A "veia cansada"}

Os fármacos e as soluções administrados por veias periféricas, em contato com o endotélio, causam lesões de diferentes graus devido à variação de $\mathrm{pH}$ e à osmolaridade, diminuindo a vida útil do acesso venoso e aumentando o risco de lesões graves como a necrose tecidual ${ }^{15}$. A expressão "veia cansada" é a denominação dada pelos técnicos de enfermagem ao acesso vascular que começa a apresentar sinais de flebite pelo uso contínuo de fármacos irritantes ao endotélio venoso. Esse é um sinal de que em breve aquela veia 
não estará mais adequada para a terapêutica e o recém-nascido precisará de uma nova punção venosa: As pessoas precisam ficar olhando, porque a veia cansa né? Eu acho que cansa, quando você está com uma medicação... Já vai ficando vermelhinho (Bernard, técnica de enfermagem).

Para lidar com o problema da "veia cansada" a equipe lança mão de uma estratégia chamada "rodízio de veias", o que acarreta a necessidade de manter o recém-nascido com mais de uma veia periférica puncionada para que seja possível a realização do rodízio enquanto uma delas descansa: Por exemplo, o gluconato de cálcio, quando está sendo infundido, a criança tem que ter mais de um acesso para que a gente possa ficar trocando, porque fatalmente vai ter flebite. (Harvey, enfermeiro).

$\mathrm{O}$ rodízio de veias é uma prática que, até o momento, não tem respaldo na literatura científica, pelo contrário, quando o recém-nascido apresenta sinais de flebite, por exemplo, ou hiperemia no trajeto do vaso, há indicação para remoção imediata do dispositivo intravenoso ${ }^{15}$. Contudo, essa estratégia é usada pela enfermagem na tentativa de "economizar veias", devido às dificuldades encontradas na manutenção do acesso venoso periférico durante a infusão de soluções irritantes para o endotélio. Na concepção da equipe, a suspensão temporária da infusão venosa, considerada um agente agressor do endotélio, pode prolongar a vida útil do vaso puncionado, tornando-o apto ao retorno da infusão após o "descanso".

Um estudo que avaliou fatores que afetam a vida útil de acessos periféricos em unidades pediátricas e neonatais do Texas evidenciou que em $35 \%$ dos casos de descontinuidade do uso do acesso vascular houve a heparinização para uso posterior, pois esperava-se que o "descanso" da veia viesse possibilitar sua reutilização. Os resultados desse estudo mostram que o "descanso da veia” é uma prática cultural, utilizada também em unidades americanas, porém sem evidência científica que a embase ${ }^{16}$. Por isso, até o presente momento, o rodízio de veias pode ser considerado um mito da terapia intravenosa e, apesar de não ser reconhecido em estudos científicos, faz sentido no sistema que organiza a cultura local, já que está diretamente relacionado à escassez de acessos venosos em recém-nascidos bem como às suas consequentes complicações.

A falta de evidências científicas sobre alguns aspectos da prática da terapia intravenosa faz com que ela seja, por vezes, embasada em fontes altamente subjetivas - como, por exemplo, opiniões do profissional, tradições institucionais, senso comum e ritos da enfermagem - ou na recomendação do fabricante dos dispositivos ${ }^{6}$.

\section{O "bom de veia"}

Num cenário onde há o desgaste da rede venosa dos recém-nascidos e o consequente aparecimento de veias "cansadas" e "difíceis", a valorização da técnica de punção venosa determina uma hierarquização na equipe de enfermagem, em que o profissional "bom de veia", com maior habilidade para realizar as punções, assume uma posição de destaque. "Bom de veia" (BDV) é a expressão usada pela equipe para nomear o profissional que é chamado para realizar a punção venosa do bebê com "veia difícil” após várias tentativas feitas por outro colega. Essa solicitação é feita quando o recém-nascido foi submetido a pelo menos quatro mal-sucedidas tentativas de punção venosa. Os profissionais chamados "bons de veia" são os que levam menos tempo para realizar as punções venosas de recém-nascidos com dificuldade de acesso venoso.

Uma das depoentes descreve o ritual de punção no qual é possível visualizar o estereótipo do profissional BDV: (...) tem gente que fala: chama fulano. E como ele consegue? Ele não é mágico, não trouxe a veia no bolso. E por que ele não foi chamado primeiro? É pessoal, eu vou puncionar porque estou com esta criança, aí, punciona uma, duas, três, quatro, e aí chama o colega do mesmo núcleo, o "bom de veia", aí ele, coitado, já pega poucas coisas, ele, por sua vez é o bom. A vaidade já sobe, que o ser humano tem o orgulho e a vaidade caminhando junto, ele tenta, puncionou mais três, puncionou sete, aí ele chama a enfermeira. Aí ela tem que fazer milagre? Não dá. É cultural, independe de rede privada ou rede pública, o bom de veia é uma coisa tão inserida no cotidiano, que você nem percebe, você fala, fulano já tentou? (Wren, médica)

$\mathrm{Na}$ divisão hierárquica do trabalho da equipe de enfermagem, a enfermeira é solicitada para realizar a punção venosa do bebê quando os técnicos e auxiliares não o conseguiram após várias tentativas. A falta de êxito numa punção venosa pode comprometer a imagem do profissional tecnicamente competente e faz com que o "BDV" tenha um status diferenciado dentro da equipe. Isso explica o fato de, só após inúmeras tentativas, os técnicos e auxiliares solicitam à enfermeira que obtenha o acesso venoso: Hoje em dia, graças a Deus, eu estou bem de veia, só quando o bebê está muito difícil, muito debilitado é que a gente não consegue, mas aí a gente passa pra enfermeira e ela consegue (Forssman, técnica de enfermagem). 
Na hierarquia dos "bons de veia", à enfermeira, líder da equipe, cabe a maior responsabilidade no que se refere a conseguir puncionar "veias difíceis" e, quando solicitada, ela tem sua competência técnica colocada à prova pela equipe, pois o recém-nascido já foi sofreu múltiplas punções pelos técnicos considerados "bons de veia". Portanto, ser "boa de veia" é um pré-requisito do enfermeiro competente, como ilustra o depoimento a seguir: Cada enfermeiro tem um jeito de administrar sua equipe, graças a Deus, os meus são bons de puncionar veia. Quando eles não conseguiram é porque o negócio tá feio, Quando chamam a gente, meu Deus, já vem barraco! Aí a gente ainda vai e consegue (Blundell, enfermeira).

$\mathrm{O}$ fato de o profissional BDV ter êxito na punção venosa periférica no momento em que é solicitado é uma solução momentânea para toda a complexidade inerente à terapêutica intravenosa e às necessidades do recém-nascido, pois, devido às características dos fármacos utilizados na UTIN, em pouco tempo essa veia periférica estará lesada, imprópria para uso e precisará ser substituída. Por outro lado, num cenário onde há escassez de veias, dor, sofrimento e outras consequências da perda do acesso vascular, o BDV também é responsável por oferecer um alívio, ainda que temporário, para os problemas advindos das perdas do acesso venoso.

No entanto, a representação cultural de que os bons profissionais são aqueles que puncionam mais veias paradoxalmente dificulta a ruptura dos profissionais com o padrão do uso da veia periférica e a banalização das múltiplas punções venosas, pois à medida que os membros da equipe só lançam mão do técnico BDV ou da enfermeira, quando já realizaram várias tentativas de punção nos bebês, esse padrão cultural mascara e, por conseguinte, agrava o problema das numerosas punções.

Uma vez que a hierarquia organiza as relações sociais, fazendo com que cada categoria tenha seu lugar a partir de estereótipos em que a dimensão do poder é fundamental para construção hierárquica ${ }^{17}$, a técnica de punção venosa legitima a identidade do profissional de enfermagem e lhe confere poder diante das relações que estruturam a prática da TIV no cotidiano da UTIN. O estereótipo do "bom ou ruim de veia" demarca o lugar que o profissional ocupa na equipe.

\section{"As marcas da terapia intravenosa" e a dinâmica de trabalho da UTIN}

As marcas da terapia intravenosa evidenciadas pela equipe e observadas durante o trabalho de campo revelam o outro lado de uma prática que, apesar de proporcionar a sobrevivência, traz inúmeras complicações para os recém-nascidos durante sua permanência na UTIN. Múltiplas punções venosas, lesões por infiltração e extravasamento, tricotomia do couro cabeludo e infecções locais e sistêmicas são ocorrências frequentes no cotidiano da UTIN e marcam recémnascidos, seus familiares e os profissionais da equipe de enfermagem, que diariamente enfrentam o desgaste físico e emocional frente à necessidade de manter recém-nascidos em TIV através de veias periféricas: Olha só, já furei, já furei, já furei, não vamos continuar fazendo isso, vamos tentar um cateterismo umbilical. (Seibert, enfermeira). (...) fura muito, não porque a gente quei$\mathrm{ra}$, mas porque a necessidade obriga, às vezes você passa horas, vem um, vem outro, tentando até conseguir (...) (Rose, auxiliar de enfermagem). Uma criança que me marcou muito foi filho de MA, que infiltrou nutrição parenteral. Foi a lesão mais feia que eu já vi numa criança, foi na cabecinha (...) muito feia a lesão.(Nightingale, enfermeira).

A prática da terapia intravenosa é emblemática do automatismo e do mecanicismo inerentes à dinâmica de trabalho da UTIN. O trabalho rotineiro e mecânico não deixa espaço para a reflexão crítica e reduz o cuidado ao recém-nascido à técnica de punção venosa. Nesse contexto o cuidado esvazia-se de sentido para a auxiliar de enfermagem, que não consegue estabelecer uma relação com o recém-nascido que necessita de terapia intravenosa. Você vira uma máquina... Eu tenho que puncionar. Eu tenho que administrar. Tem uma hora que você não pensa nem na dor que ele está sentindo. Você tem que fazer. Porque alguém diz que é muito importante para ele que faça assim (...) (Dudrick, auxiliar de enfermagem).

A equipe demonstrou ter consciência de marcas e repercussões da prática da terapia intravenosa para a saúde do recém-nascido, porém, o fato de estarem imersos na engrenagem da UTIN, numa dinâmica de trabalho mecanizada, produto de uma cultura ainda arraigada no modelo tecnicista de cuidar, mantém os profissionais inertes no emaranhado de significados: $E$ do próprio sistema da UTI, porque você vê, hoje lá está super calmo, as luzes estão apagadas. Você às vezes está no automático e não se toca que agora dá pra eu fazer isso, dá pra eu enrolar ele, dá tempo, enten- 
deu? Então as pessoas às vezes ligam o automático (Denis, técnica de enfermagem).

O enfermeiro, responsável legal pela administração da TIV, e sua equipe enfrentam elevado índice de estresse advindo das falhas do processo de trabalho na $\mathrm{UTIN}^{18}$. Isso reflete diretamente no planejamento dos cuidados e na administração do plano terapêutico dos recém-nascidos. Esse contexto dificulta as reflexões e o desenvolvimento das potencialidades dos profissionais para a re-significação da prática da terapia intravenosa, absolutamente necessária na implementação de mudanças que promovam um cuidado seguro no contexto da unidade: Quando você está fazendo uma medicação venosa, uma bomba alarma, você fica desesperado pra saber o que está acontecendo. O funcionário está estressado, você precisa de alguém para te auxiliar numa punção venosa, é uma dificuldade, a medicação tende a atrasar os horários, se for uma criança difícil de veia a gente já tem uma previsão de que, o antibiótico vai atrasar. Isso tudo fica na nossa cabeça, pontuando o tempo todo na nossa consciência, tem que entrar o soro, tem que entrar o antibiótico, tem que entrar, tem que entrar! (Harvey, enfermeiro)

A escassez de acessos venosos agrava o problema que a equipe enfrenta para infundir múltiplos fármacos num curto período de tempo. A infusão dos antimicrobianos sofre atrasos importantes e o plano terapêutico não é possível de ser cumprido levando aos erros de medicação. Além disso, a perda frequente dos acessos venosos e as múltiplas punções são grandes obstáculos na implementação do cuidado humanizado e voltado para o desenvolvimento, pois interferem diretamente na aplicação dos princípios norteadores desse modelo de cuidar, principalmente a diminuição do manuseio, garantia de períodos de sono e repouso para os recém-nascidos e a diminuição dos estímulos dolorosos.

\section{Humanização - "As coisas ainda não foram conectadas"}

Uma vez que a unidade estudada é referência para a política de humanização da assistência aos recém-nascidos de baixo-peso, a equipe destacou as interfaces do paradigma do cuidado humanizado com a prática da terapia intravenosa, deslocando o recém-nascido para o centro da teia e anunciando alguns caminhos, ainda que incipientes, em direção ao movimento de resignificação.

Essas interfaces estão presentes na aplicação de medidas não farmacológicas de prevenção da dor relacionada às punções venosas, tais como a utilização de glicose por via oral ou a contenção e o enrolamento do bebê durante o procedimento de punção venosa.

Os depoentes percebem que as mudanças de atitude no que diz respeito à prevenção da dor relacionada às punções venosas é umas das condições para tornar o cuidado mais humano, nos termos que preconiza a política de atenção humanizada ao recém-nascido de baixo peso. Embora venha sendo gradativamente adotada pelas equipes, essa prática ainda não é instituída na maioria dos plantões: Na questão da humanização que tanto se preconiza hoje em dia, as pessoas também estão bastante envolvidas (...) não sei se isso é uma visão minha ou não. Ainda há pouco, tivemos que puncionar outro acesso, aí a auxiliar ficou do meu lado, utilizamos todo o protocolo de humanização, enrolamento, sucção não nutritiva, e puncionamos, enfim a gente vê que tem uma mudança, mas, acho que isso é uma questão de reflexão pessoal e mudança de comportamento, nem todos os funcionários agem dessa forma (Latta, Enfermeiro).

A incorporação parcial das medidas preconizadas pela política institucional parece estar associada ao choque à transição entre modelos assistenciais vivenciados na unidade. Ficou claro, nas falas, que existe um conflito entre o paradigma tecnicista (dominante na UTIN), representado pelo "cuidado mecânico", invasivo, imediatista e impessoal, e o cuidado com o recém-nascido de modo individualizado, pois o percebe como ser único ${ }^{19}$. A gente tenta manter as regras de humanização, do enrolamento, do aconchego e tudo mais, mas às vezes, não dá. Nem sempre você consegue, mas se tivéssemos esses processos em congruência, com a humanização, você teria a análise do momento de cada bebê mais ativa, mais viva, mais forte nas pessoas. Eu acho que é uma coisa que pode acontecer, mas as pessoas ainda não acordaram para este detalhe. Eu acho que as coisas ainda não foram conectadas (Seibert, enfermeira).

Por outro lado, ainda que conflituosa, a convivência entre os dois modelos promove, mesmo timidamente, a construção de novas teias de significado (ou a ressignificação) do cuidar do recém-nascido na UTIN, permitindo a emergência de um novo modelo de atenção, em que o cuidado e a tecnologia não se opõem, mas se complementam. Uma simples gota de glicose, alivia a expressão de dor da criança de tal maneira. Eu procuro sempre dentro do possivel puncionar acompanhado de outra pessoa. Tem que ter uma pessoa do meu lado, com o dedo na boca, dando gotinhas de açúcar. Eu fico revoltado de ver uma pessoa puncionando sozinha. (Harvey, enfermeiro) 
A incorporação de novas práticas que melhoram a qualidade da assistência ao recém-nascido é potencializada quando os profissionais refletem sobre sua própria prática e têm a oportunidade de experimentar outras formas de cuidar. Ao constatar que uma simples gota de glicose alivia a dor do recém-nascido, o enfermeiro Harvey passa a acreditar que é possível promover um cuidado com menos dor e sofrimento, não só para o bebê, mas também para ele.

Ao relatar como percebe o alívio da dor em um recém-nascido que recebe glicose via oral durante a punção venosa, o enfermeiro anuncia que há a necessidade da ressignificação de alguns sentidos atribuídos à prática da punção venosa. Por exemplo, solicitar a presença do colega durante uma punção não significa "não ser bom de veia”, mas centrar o cuidado no recém-nascido, e não na técnica, tornando-a menos dolorosa para o bebê e para quem a realiza. "O agir individual também traz a expressão dos aspectos culturais, sociais, afetivos e políticos que estão inter-relacionados nas relações de cuidado ${ }^{20}$ ".

A crença de que o Homem se completa e se acaba através da cultura porque cada fio da teia de significados tem inter-relação com símbolos que são interpretados a todo o momento, produzindo suas ações ${ }^{7}$, é fundamental na construção de uma nova cultura de cuidado na unidade, na qual o profissional se sente sujeito ativo e responsável pelo processo de mudança tão desacreditado no âmbito dos serviços públicos de saúde.

\section{Conclusão}

O olhar semiótico e de estranhamento possibilitou a apreensão dos diversos códigos e da maneira como eles são entrelaçados, formando a teia de significados que revela os modos como os atores sociais vivenciam a prática da terapia intravenosa no espaço da UTIN. A prática da TIV é estruturada a partir de vários significados culturais construídos pela equipe.

No centro da teia localiza-se a punção venosa periférica, principal símbolo da terapia intravenosa, pois a partir da valorização da técnica de punção é que se estabelecem as interações que determinam o modelo de cuidado de recém-nascidos que necessitam de terapia intravenosa.

Na Figura 1, encontram-se ilustrados os significados atribuídos à prática da terapia intravenosa na UTIN, responsáveis por formar o sistema de codificação cultural no qual ela se estrutura. Os códigos estão amarrados uns aos outros forman- do a teia de significados apreendidos, juntamente com as repercussões desse modelo de cuidar na saúde dos recém-nascidos, e são produtos das interações que surgem à medida que a equipe vivencia os desafios da prática da TIV, fundamentandoa nas punções venosas periféricas. Sendo assim, amarradas à teia de significados, observamos as complicações advindas da prática da TIV e as dificuldades que a equipe enfrenta para desenvolvê-la.

A repetição de alguns termos no esquema procura ilustrar a dinâmica da construção do sistema de códigos pelos sujeitos, pois em qualquer lugar da teia (cujo centro é a punção venosa periférica), os significados estão entrelaçados influenciando e sendo e influenciados uns pelos outros, mantendo o padrão cultural que estrutura prática da TIV e repercute de diferentes maneiras no cuidado do recém-nascido. Por exemplo: o termo "veinha", que representa a banalização da punção, evolui para "veia difícil”, que precisa do "bom de veia" por causa do esgotamento da rede venosa.

A metáfora da teia, tal qual no pensamento de Geertz, procura mostrar como, a partir do emaranhado de significados, os sujeitos reproduzem o padrão cultural que sustenta a prática da TIV na unidade e suas repercussões para o cuidado do recém-nascido. Desta forma, a leitura etnográfica, ainda que de forma inacabada, possibilitou a apreensão do sistema de codificação cultural que norteia essa prática no cenário de estudo. A análise da prática da TIV, na perspectiva dos significados, possibilitou ultrapassar os seus limites de função terapêutica e evidenciar as interações que desvelam conflitos, negociações e dilemas vivenciados pela equipe da UTIN ${ }^{2}$.

A centralidade e a banalização da punção venosa periférica, representada pelo código "veinha", leva os recém-nascidos a sofrerem múltiplas punções e ao esgotamento da rede venosa, fazendo com que a equipe produza outros significados derivados dessa centralidade, como a "veia difícil" e o "bom de veia". A veia difícil surge a partir do esgotamento da rede venosa do bebê e do significado atribuído ao profissional "bom de veia", pois, ao mesmo tempo em que traz alívio para a equipe quando tem êxito na punção venosa, ele retroalimenta o padrão cultural de valorização da punção venosa periférica de repetição.

O rodízio de veias, (para poupar a "veia cansada"), conduta considerada um mito da terapia intravenosa, apesar de não ter sustentação em bases científicas, adia temporariamente a dor e o sofrimento do recém-nascido, da equipe e da família causados pelas múltiplas punções. 


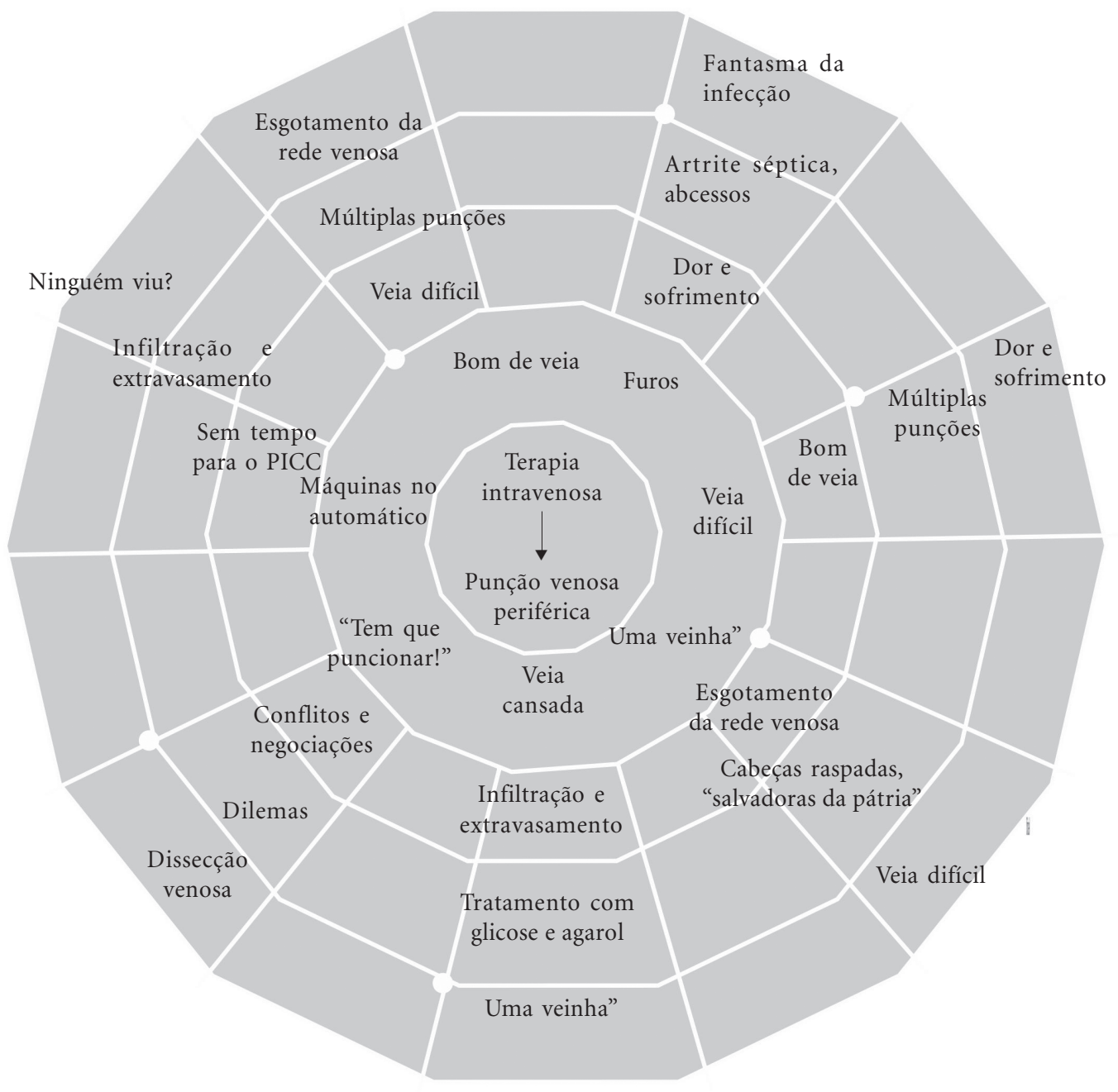

Figura 1. Significados atribuídos à prática da terapia intravenosa

A repetição de alguns termos no esquema procura ilustrar a dinâmica da construção do sistema de códigos pelos sujeitos, pois em qualquer lugar da teia (cujo centro é a punção venosa periférica), os significados estão entrelaçados influenciando e sendo e influenciados uns pelos outros, mantendo o padrão cultural que estrutura prática da terapia intravenosa e repercute de diferentes maneiras no cuidado do recém-nascido.

Por exemplo: o termo "veinha" que representa a banalização da punção, com o tempo passa a se chamar veia difícil, que precisa do "bom de veia" por causa do esgotamento da rede venosa. A veia cansada, que sofreu infiltração/extravasamento e foi tratada com agarol e glicose, era só "uma veinha".

A equipe demonstrou ter conhecimento das medidas não farmacológicas para minimizar a dor relacionada às punções venosas. Contudo, tais medidas, ainda não são implantadas em sua totalidade, embora a unidade seja de referência para o Método-Canguru.
Os resultados mostraram que, apesar da introdução do cateter central de inserção periférica nas unidades do município com a capacitação dos enfermeiros e a elaboração de protocolo, as medidas adotadas não foram suficientes para a incorporação dessa tecnologia no cuidado dos recém- 
nascidos de forma a minimizar os danos causados pelo uso frequente dos acessos venosos periféricos. A incorporação de novas tecnologias em TIV é de vital importância para o cuidado, porém, para que possam beneficiar os recém-nascidos e a equipe é preciso que seja acompanhada de uma revisão de práticas no espaço da UTIN. Uma postura crítica e reflexiva deve ser adotada em busca de racionalização, aquisição e incorporação de novas tecnologias e ainda de uma avaliação, sob o ponto de vista ético, dos custos, da qualidade da assistência, dos benefícios, das limitações, dos riscos e da adequação às necessidades da população ${ }^{21}$.
A ressignificação da prática da TIV, com base nos achados deste estudo, será possível à medida que os sujeitos, refletirem sobre a prática e reavaliarem os padrões culturais nos quais ela se estrutura de modo a que possam ser agentes ativos de mudanças.

A produção e divulgação de conhecimentos sobre a prática da TIV é fundamental para a formulação de políticas públicas de saúde que visem à humanização da assistência, redução de agravos e à promoção de um crescimento e um desenvolvimento saudáveis para recém-nascidos egressos de unidades neonatais.

\section{Colaboradores}

EC Rodrigues participou da concepção, do trabalho de campo, do delineamento e da aprovação da versão final do artigo para publicação. SR Cunha e R Gomes participaram da concepção, do delineamento, da revisão crítica e da aprovação da versão final do artigo para publicação.

\section{Agradecimento}

A Marco Aurélio Pinna de Carvalho (in memoriam) pela confecção gráfica da "Teia de Significados". 


\section{Referências}

1. Silva RN. Cuidados voltados para o desenvolvimento do pré-termo na UTI neonatal. In. Alves Filho N, Trindade OR, organizadores. Avanços em Perinatologia. Rio de Janeiro: Guanabara Koogan; 2005. p. $265-289$

2. Rodrigues EC. "Perdeu a Veia" - Os significados da prática da terapia intravenosa numa unidade de terapia intensiva neonatal do Rio de Janeiro [tese]. Rio de Janeiro (RJ): Instituto Fernandes Figueira; 2008.

3. Pedreira MLG, Chaud MN. Terapia intravenosa em Pediatria: subsídios para a prática de enfermagem. Acta Paul. Enf 2004; 17(2): 222-228.

4. Menezes SO. Avaliação do acesso vascular em neonatos com menos de $1500 \mathrm{~g}$ internados em unidades neonatais da SMS do Rio de Janeiro. [dissertação]. Rio de Janeiro (RJ): Instituto Fernandes Figueira; 2005.

5. Cabral IE, Rodrigues EC. O método mãe canguru em uma maternidade do Rio de Janeiro, 2000-2002: Necessidades da criança e demanda de educação em saúde para os pais. Texto contexto - enferm 2006; 15(4):629-636.

6. Hanchett M. Infusion Nursing's Greatest Barrier: The Lack of Evidence to Support Evidence-Based Practice. Topic in Advanced Practice Nursing Journal 2005; 5(3):1-6

7. Geertz C. A interpretação das culturas. Rio de Janeiro: LTC; 1989.

8. Helman CG. Cultura em Saúde \& Doença. Porto Alegre: Artmed; 2003.

9. Deslandes SF, Gomes R. A pesquisa qualitativa nos serviços de saúde:notas teóricas. In: Bosi MLM, Mercado FJ, organizadores. Pesquisa Qualitativa nos Serviços de Saúde. Petrópolis: Vozes; 2004. p. 99-120.

10. Sarmento MJ. O estudo de caso etnográfico em educação. In: Zago N, Carvalho MP, Vilela RAT, organizadores. Itinerários de pesquisa. Rio de Janeiro: DP\&A; 2003.

11. André MEDA. Etnografia da Prática Escolar. São Paulo: Papirus; 2003.

12. Lamy ZC, Gomes MASM, Gianini NOM, Hennig MAS. Atenção humanizada ao recém-nascido de baixo peso-Método Canguru: A Proposta Brasileira. Cien Saude Colet 2005; 10(3):659-668.

13. Vaghetti HH, Padilha MIC, Maia ARC. Geertz's theoretical-methodological reference as an option for studying culture in hospital organizations. Cuad. Adm 2006; 19(32):179-194.
14. Gomes R. Análise interpretativa de dados de pesquisa qualitativa. In: Minayo MCS, Deslandes SFD, Gomes R. Pesquisa Social: Teoria, método e criatividade. Petrópolis: Vozes; 2007.

15. Thigpen JL. Peripheral Intravenous Extravasations: Nursing Procedure for Inicial Treatment. Neonatal Network 2007; 26(6):379-384.

16. Smith AB, Faulk DW. Factors affecting the life span of peripheral intravenous line in hospitalized infants. Pediatric Nursing 1994; 20(6):543-547.

17. Velho G. Observando o familiar. In: Nunes EO, organizador. A aventura sociológica. Rio de Janeiro: Zahar Editores; 1978.

18. Erdmann AL, Andrade SR, Mello ALF, Meirelles, BHS. Gestão das práticas de saúde na perspectiva do cuidado complexo. Texto contexto - enferm. 2006; 15(3):483-491.

19. Moreira DS, Magnago RF, Sakae TM, Magajewski FRL. Prevalência da síndrome de burnout em trabalhadores de enfermagem de um hospital de grande porte da Região Sul do Brasil. Cad Saude Publica 2009; 25(7):1559-1568.

20. Gaiva MAM. O cuidar em unidades de cuidados intensivos neonatais: em busca de um cuidado ético e humanizado. Cogitare enferm. 2006; 11(1):61-66.

21. Barra, DCC, Nascimento ERP, Martins JJ, Albuquerque GL, Erdmann AL. Evoluçâo histórica e impacto da tecnologia na área da saúde e da enfermagem. Revista Eletrônica de Enfermagem [periódico na internet]. 2006 [acessado out 2009];8(3):[cerca de 9p.].Disponível em http://www.fen.ufg.br/revista/revista8_3/v8n3a13.html

Artigo apresentado em 15/03/2011

Aprovado em 23/05/2011

Versão final apresentada em 30/05/2011 